Brit. J. vener. Dis. (1958), 34, 107.

\title{
EVALUATION OF THERAPY IN NON-SPECIFIC URETHRITIS*
}

\author{
BY \\ W. FOWLER \\ From the General Hospital, Birmingham, and the Royal Hospital, Wolverhampton
}

This paper is concerned with the value of treatment in cases of non-specific urethritis (N.S.U.) which cannot be attributed to physical or chemical trauma, infection by the herpes simplex virus or by bacteria known to cause urethritis, protozoal, or mycotic infections, or idiosyncrasy to articles of diet, and is not secondary to meatal or urethral stricture or to infection of the upper urinary tract. For almost 7 years now my standard treatment for N.S.U. of uncertain aetiology has been potassium citrate gr. 20 and, if warranted by symptoms, liquid extract of hyoscyamus minims 5 in a simple mixture three times daily. The results of this treatment are given below and compared with those of sulphonamides and antibiotics in an attempt to reach a proper appreciation of the value of treatment and especially of specific kinds of treatment in N.S.U. of this type.

Recorded opinion is far from unanimous regarding the efficacy of treatment in N.S.U. Harkness (1953) says that urethro-vesical irrigations have to be given twice daily for 2 to 8 weeks to effect cure. Prebble (1957) states that one irrigation daily for 3 to 7 days will cure 85 per cent. of cases. Harkness (1953) finds that sulphonamide therapy is useless unless supplemented by grande lavage. Babione and Graham (1952) claim that sulphadiazine will cure some 90 per cent. of cases in a very few days provided certain simple hygienic rules are observed. Shaffer (1954) reports that no antibiotic or combination of antibiotics has been uniformly effective in his hands. Harkness (1953) believes that specific therapy is provided by the antibiotics derived from lower grade fungi; he found that terramycin was the most effective of these antibiotics and it is pertinent to note that the rate of cure he gives for terramycin is almost the same as that recorded by Prebble (1957) for irrigation therapy.

\section{Material}

242 cases of N.S.U. investigated personally and treated with the potassium citrate mixture have been

*Received for publication December 2, 1957. selected for study. None of these cases presented any obvious local or systemic complications on admission or later developed conjunctivitis, arthritis, or keratodermia blennorrhagica. Otherwise the cases have been selected simply because they were under observation for at least 4 weeks. The exclusion of Reiter's syndrome from the study will not bias the results in favour of potassium citrate therapy as neither sulphonamides nor antibiotics influence the course of this syndrome (Fowler and Knight, 1956).

The urethral discharge was profuse and purulent in 25 cases $(10.3$ per cent.), and mucopurulent or mucoid and occasionally profuse but usually moderate or scanty in the others. $\mathbf{7 4 . 6}$ per cent. of the cases attended hospital within 7 days of the onset of the illness, $15 \cdot 5$ per cent attended within 14 days, and 5.8 per cent. attended within 21 days, while the remainder did not seek treatment until the condition had been present for more than 21 days.

\section{Method}

The urethral discharge was examined in Gramstained, methyl-violet stained (Fowler, 1953), and wet films, and was cultured on chocolate agar and on blood agar. If mycotic elements were constantly present in films, the discharge was also cultured on Sabouraud's medium and on corn-meal agar. Urine was collected in two glasses, the first glass being filled. After about $2 \mathrm{ml}$. urine had been passed into the first glass, a specimen was taken (with sterile precautions) for bacteriological examination, including the examination of wet films. Chemical analysis was also carried out on this specimen. If the two-glass urine test did not indicate clearly that the affection was limited to the lower urinary tract, a three-glass test was carried out as soon as possible. Unless the urethroscopic appearances were those of sago-grain urethritis, the above bacteriological investigations were carried out at each visit; in addition, the first glass of urine having been allowed to stand for some time, any deposit was centrifuged and examined in wet and stained films. Urethroscopy was carried out on admission 
or at the second visit, and then at regular intervals during the course of the illness. The initial examination included gentle palpation of the prostate. Blood examinations included serological tests for syphilis and gonorrhoea, and white cell counts, serum protein estimations (including electrophoretic analysis and, latterly, fibrinogen estimation) were carried out at weekly intervals. In addition to these investigations, urethral scrapings and washings were examined in films and cultures and on a number of occasions injected into fertile eggs and mice. Intravenous pyelography was carried out whenever there was a history of repeated attacks of urethritis even if there were no clinical signs of involvement of the upper urinary tract.

If the urethritis persisted for 4 weeks, a curved sound was passed into the bladder to exclude stricture of the posterior urethra. This procedure was, of course, carried out earlier if there were any suggestive symptoms. The prostatic secretion was examined 4 weeks after apparent cure, a suitably sized bougie was passed into the bladder, and the morning urine (after alcohol or ginger ale the previous evening) was examined.

The potassium citrate mixture was prescribed until signs disappeared. Patients were advised to abstain from alcohol and to avoid sexual excitement for at least 4 weeks after apparent cure.

As the aetiology is unknown there can be no certain criteria for cure. In this study, cases were regarded as cured when signs disappeared and did not recur during a subsequent observation period of at least 3 weeks, and especially when alcohol, coitus, and the passage of a curved sound failed to provoke a relapse. So far as is known none of the cases regarded as cured relapsed within 3 months of the last attendance at the clinic.

\section{Results}

Table I shows the number of patients who recovered each week and the rate of cure at the end of each week up to the fifth week after admission.

TABLE I

PERCENTAGE RATES OF CURE WITH POTASSIUM CITRATE

\begin{tabular}{c|c|c|c|c|c|c}
\hline $\begin{array}{c}\text { Days after } \\
\text { Admission }\end{array}$ & 7 & 14 & 21 & 28 & 35 & $\begin{array}{c}\text { Total } \\
\text { No. Cured }\end{array}$ \\
\hline $\begin{array}{c}\text { Cases Cured } \\
\text { each Week }\end{array}$ & 66 & 58 & 28 & 21 & 18 & 191 \\
\hline $\begin{array}{c}\text { Percentage } \\
\text { Rates of Cure }\end{array}$ & $27 \cdot 6$ & $51 \cdot 3$ & $62 \cdot 8$ & $71 \cdot 3$ & $78 \cdot 7$ & - \\
\hline
\end{tabular}

Gartman and Leibovitz (1955) found that spontaneous cure took place gradually, whereas signs and symptoms cleared abruptly with successful antibiotic therapy. With potassium citrate therapy cure occurred in one of the following ways:

(1) Abruptly;

(2) Gradually;

(3) Signs cleared and recurred repeatedly for some weeks before finally disappearing.

The period of observation after signs cleared in the 191 cases classed as cures was: 3 weeks -69 cases, 4 weeks -63 cases, 1 to 2 months -45 cases, over 2 months -14 cases.

The prostatic secretion contained an excessive number of pus cells in six (6.2 per cent.) of 96 of these cases 4 to 5 weeks after signs of urethritis cleared. This finding was disregarded when determining cure.

51 cases took longer than 5 weeks to recover. Signs of urethritis cleared within 2 weeks of admission in 24 of these cases $(9.9$ per cent. of whole series) and during the next 3 weeks in another six cases. Of these thirty cases eight were free from signs for only 2 weeks, and seven for only 3 weeks. Ten of the remaining cases relapsed after 1 to 2 months and the others in 2 to 3 months. The urethral discharge reappeared some 12 hours after prostatic massage in a patient who had been free from signs of urethritis for 4 weeks, and 13 days later he developed acute epididymo-orchitis.

Table II gives the results obtained with:

(1) Sulphonamides 1 g. 6-hrly. for 5 days;

(2) Streptomycin $1 \mathrm{~g}$. daily for 2 to 4 days;

(3) Terramycin 0.5 g. 6-hrly. for 4 days.

TABLE II

PERCENTAGE RATES OF CURE WITH OTHER DRUGS

\begin{tabular}{|c|c|c|c|c|c|c|}
\hline \multirow{2}{*}{\multicolumn{3}{|c|}{ Therapy }} & \multirow{2}{*}{$\begin{array}{l}\text { No. of } \\
\text { Cases }\end{array}$} & \multicolumn{3}{|c|}{ Days after Admission } \\
\hline & & & & $7-8^{*}$ & $14-15$ & $21-22$ \\
\hline \multicolumn{3}{|c|}{ Sulphonamides .. } & 141 & $31 \cdot 2$ & $53 \cdot 1$ & $61 \cdot 6$ \\
\hline Streptomycin & . & . & 37 & $28 \cdot 9$ & $52 \cdot 6$ & $57 \cdot 8$ \\
\hline Terramycin. . & $\cdots$ & .. & 35 & $34 \cdot 2$ & $65 \cdot 7$ & $74 \cdot 2$ \\
\hline
\end{tabular}

*7 days after treatment started.

The terramycin results are from a consecutive series of cases of N.S.U. of obscure origin treated with this antibiotic. The sulphonamide and streptomycin cases were selected from clinic records of the past 11 years and as they were not so intensively investigated as the terramycin and potassium citrate cases more of them may have been due to Trichomonas vaginalis. 
The duration of the illness before admission was:

1 to 7 days in 74 per cent. of cases (terramycin cases71 per cent.);

8 to 14 days in 17 per cent. of cases (terramycin cases19 per cent.);

15 to 21 days in $2 \cdot 8$ per cent. of cases (terramycin cases -4 per cent.).

The urethral discharge was profuse and purulent in 26 cases ( 12 per cent.) of the 213 cases shown in Table II. The minimum observation period and the criteria of cure were as for Table I.

Seven ( 7.6 per cent.) of 92 of the cases shown as cured in Table II, including two of eighteen cases treated with terramycin, had an excessive number of pus cells in the prostatic secretion 4 to 5 weeks after the signs of urethritis had cleared. I have ignored this finding in determining cure, as I do not believe that its significance can be properly appreciated at present.

One patient who appeared to have responded to sulphonamide therapy developed acute epididymoorchitis after having been free from signs of urethritis for 2 months. There was no association with prostatic massage in this instance.

Because sulphonamides or antibiotics act quickly, if at all, during the few days in which they are administered, the rates of cure in Table II have not been shown beyond the third week after admission. However, signs of urethritis do not disappear at once when the cause of the condition has been removed, although Willcox $(1955,1957)$ suggests that this is so by his method of presenting his findings. On the contrary, the time taken for signs to disappear after successful treatment will depend upon the degree of inflammatory involvement of the urethra. In my opinion, this is most unlikely to exceed 3 weeks and I shall later attempt to show that residual signs disappear within 2 weeks of the start of treatment.

\section{Discussion}

Non-specific urethritis is self-limiting (Gartman and Leibovitz, 1955), and the response to treatment cannot be followed bacteriologically. The condition has a tendency at times to clear and recur, and I therefore suggest that, before one treatment can be compared properly with another, the following conditions must be fulfilled:

(1) The respective rates of cure should be reached at comparable times after admission;

(2) The duration of the illness before the patient's admission should also be comparable.

(3) The rates of cure should be finally determined only after the cases have been under observa- tion for some weeks, and preferably some months, after the signs of urethritis cleared.

These conditions are satisfied in Tables I and II, but the value of this comparison may be limited for the following reasons:

(1) The rates of cure were obtained over a period of years and not in a single therapeutic trial in which the patients were allotted to the different treatment groups in turn;

(2) The sulphonamide and streptomycin series may contain a greater proportion of cases due to Trichomonas vaginalis than the other two series;

(3) The minimum observation time after signs cleared may be too short as, of the thirty cases known to have relapsed after treatment with potassium citrate, fifteen did not do so until 4 or more weeks after the initial attack cleared.

If Tables I and II are compared, it will be seen that the rates of cure with sulphonamides and streptomycin do not differ from the rate of cure with potassium citrate at comparable times after admission, while the rate of cure with terramycin is only 14 per cent. higher than that with the alkaline therapy.

These findings hardly support the belief that terramycin provides specific therapy for the condition, as if potassium citrate has any action at all in this type of urethritis it is most unlikely to be a specific one. The fact that epididymo-orchitis was not a feature of any of the cases treated with streptomycin or terramycin is of no significance. Only small numbers of cases received these antibiotics, and epididymo-orchitis did not occur in any of the 113 patients from whom Gartman and Leibovitz (1955) withheld treatment. Indeed, Doyle, Gill, and Laird (1957) have recently recorded the occurrence of this complication after treatment with terramycin.

Table III (overleaf) shows the rates of cure recorded for various treatments in Great Britain and abroad.

Lyall (1953) claimed that $85 \cdot 4$ per cent ( 94 cases) of 110 cases were cured by combined streptomycin and sulphonamide therapy, but as eighteen of the 94 cases required further treatment the cure rate was only 69 per cent.

Table III shows that the findings of Gartman and Leibovitz (1955) indicate that penicillin not only fails to cure N.S.U. but actually delays healing. This is a fallacious conclusion resulting from the fact that Gartman and Leibovitz (1955) ignored the conditions suggested as essential for any comparison between treatments. 
TABLE III

PERCENTAGE RATES OF CURE RECORDED IN THE LITERATURE

\begin{tabular}{|c|c|c|c|c|c|c|c|c|c|c|c|}
\hline \multirow{2}{*}{\multicolumn{2}{|c|}{ Therapy }} & \multicolumn{10}{|c|}{ Authors and Dates } \\
\hline & & $\begin{array}{c}\text { Harkness } \\
(1953)\end{array}$ & $\begin{array}{l}\text { Willcox } \\
\text { (1957) }\end{array}$ & $\begin{array}{c}\text { Jelinek } \\
\text { (1957) }\end{array}$ & $\begin{array}{l}\text { Doyle, } \\
\text { Gill, and } \\
\text { Laird } \\
(1957)\end{array}$ & $\begin{array}{l}\text { Prebble } \\
\text { (1957) }\end{array}$ & $\begin{array}{c}\text { Lyall } \\
(1953)\end{array}$ & $\begin{array}{l}\text { Jensen } \\
(1954)\end{array}$ & $\begin{array}{c}\text { Gartman } \\
\text { and } \\
\text { Leibovitz } \\
\text { (1955) }\end{array}$ & $\begin{array}{c}\text { Babione } \\
\text { and } \\
\text { Graham } \\
(1952)\end{array}$ & $\begin{array}{c}\text { Kershaw } \\
\text { and } \\
\text { Lindsay } \\
(1956)\end{array}$ \\
\hline Sulphonamides & $\cdots$ & - & 60 & 60 & 21 & - & - & 一 & - & 90 & - \\
\hline Penicillin $\ldots$ & $\cdots$ & - & 60 & - & 一 & - & - & - & 41 & - & - \\
\hline Streptomycin & $\cdots$ & 38 & 62 & 70 & 61 & - & - & - & 47 & - & - \\
\hline Chloramphenicol & $\cdots$ & 31 & 59 & - & - & - & - & - & 78 & - & - \\
\hline Aureomycin & $\cdots$ & 59 & 81 & - & - & - & - & 66 & 79 & - & 75 \\
\hline Terramycin . . & $\cdots$ & 87 & 84 & 77 & 91 & - & - & - & 70 & - & 64 \\
\hline Tetracycline & $\cdots$ & - & 81 & 62 & - & - & - & - & - & - & - \\
\hline $\begin{array}{l}\text { Streptomycin }+ \\
\text { Sulphonamides }\end{array}$ & $\cdots$ & - & - & 78 & 76 & 76 & 69 & - & 一 & - & 81 \\
\hline Erythromycin & $\cdots$ & - & 72 & - & - & 60 & - & - & - & - & - \\
\hline Pot. cit. or Placebo & & - & 31 & - & 14 & - & - & 22 & - & - & - \\
\hline Irrigations & $\cdots$ & - & - & - & - & 85 & - & - & - & - & - \\
\hline No Treatment & $\ldots$ & - & - & - & - & - & - & - & 49 & - & 一 \\
\hline
\end{tabular}

For one or more of the following reasons none of the results in Table III can be compared with those in Tables I or II:

(1) Most of the rates of cure in Table III were obtained in cases presenting non-gonococcal urethral discharges irrespective of aetiology, and in the present state of knowledge it is impossible to determine how this would affect the comparison;

(2) The duration of the illness before admission is seldom mentioned;

(3) Bias was introduced into one therapeutic trial and possibly into another;

(4) Many cases were not followed up beyond the day on which signs of urethritis disappeared.

For these and certain other reasons, no useful purpose would be served by attempting to compare the results of the various authors in Table III with each other, but the findings of Prebble (1957) must be discussed. The only information given about these cases is that they were in no way selected and had received no treatment before admission. As it is not certain that the three series were comparable in all respects, it cannot be concluded that irrigation therapy is superior to streptomycin combined with sulphonamides or to erythromycin. The importance of Prebble's communication lies in the fact that, of 73 patients given one urethro-vesical irrigation with hydrarg. oxycyan. $1 / 8,000$ daily for 3 to 7 days, 62 (85 per cent.) were free from signs of urethritis 15 days after starting treatment. Many of these cases were not followed up after the fifteenth day, so that the rate of cure may be lower than 85 per cent. Nevertheless this finding must cause the high rates of cure credited to certain antibiotics and to streptomycin combined with sulphonamides to be viewed with suspicion, as it is inconceivable that irrigation therapy could have any specific action. Indeed I find it difficult to believe that this treatment could have any curative action at all, and especially when it was given for 3 days only. I believe that the cures which followed this irrigation treatment were in fact spontaneous.

I am also of the opinion that the data in Table I closely reflects the self-limiting tendency of N.S.U. in Great Britain. My reasons are as follows:

(1) Potassium citrate is unlikely to have any specific action;

(2) It is improbable that any curative action could be exerted by the slightly alkaline urine in its rapid passage through the urethra during micturition;

(3) It is also improbable that the $\mathrm{pH}$ of the tissues could be so altered by the alkaline therapy as to produce an unfavourable environment for any urethral infection;

(4) The psychological effect of the medicine cannot be estimated but is unlikely to be significant. 
The manner in which signs disappeared during potassium citrate therapy and the rate at which cure occurred during the 5-week period suggest that recovery was spontaneous rather than due to therapy. Further, Tables I and II show that the rate of cure of terramycin increased more rapidly than that of potassium citrate during the first 2 weeks, but that during the third week the percentage increase in these rates of cure was about the same. I suggest that this finding indicates that residual signs persisted for up to 14 days after successful terramycin therapy and that the cures after this were spontaneous.

The spontaneous cure rate and the cure rates of placebos and potassium citrate shown in Table III do not prove that the findings in Table I or my interpretation of them is wrong. It is obviously important, when comparing spontaneous cure rates after admission, to take into account the duration of the illness before admission. Unfortunately Gartman and Leibovitz (1955) do not give this information so that it is not possible to compare the spontaneous cure rate in their cases with the findings in Table I. 60 per cent. of the cases reported by Jensen (1954), 74 per cent. of the cases in Table I, and 85 per cent. of the cases of Doyle, Gill, and Laird (1957) attended hospital within 7 days of the onset of the illness. Thus the fact that I obtained better results with potassium citrate than Doyle and his co-workers obtained with this therapy, or Jensen (1954) obtained with saline injections, cannot be attributed to differences in the duration of the illness before admission.

A strict comparison is not possible between the findings in Table $I$ and the results given by Jensen (1954) and by Doyle, Gill, and Laird (1957) for placebos and potassium citrate respectively, because the latter results were obtained in cases presenting non-gonococcal urethral discharges irrespective of aetiology.

It is doubtful whether any conclusions can be drawn from the experiment of Jensen (1954), as 34 of the 68 cases studied were under observation for apparently only 7 days, while another twelve cases defaulted after having been under observation for 14 days. Doyle, Gill, and Laird (1957) are of the opinion that many patients who default do so because they are cured; this must be so in many instances and Jensen's spontaneous cure rate may well have teen higher than he estimated.

At an early stage in their therapeutic trial Doyle, Gill, and Laird (1957) decided that some cases due for potassium citrate therapy demanded a potentially more potent remedy (namely terramycin 250 mgs. 6-hrly. for 4 days) because their symptoms were very severe. As a result the potassium citrate series contained only 35 cases, compared with 61 cases in the terramycin series and 49 to 56 cases in the other series. These authors believe that any bias introduced by this selection of cases is insufficient in itself to explain the greatly superior results which they obtained with terramycin (Table III). This I cannot accept, for I believe that if any selection of cases is introduced into a therapeutic trial the object of the trial is lost and no significance can be attached to the findings.

I cannot comment on the rate of cure which Willcox (1957) gives for placebos. I can find nothing in his various papers (Willcox 1955, 1956, 1957) to indicate the nature of these placebos. Nor does Willcox (1957) mention the type of case treated, the duration of the illness before admission, or the time after admission at which this rate of cure was reached. Without this information it is impossible to compare his results with mine.

I suggest, therefore, that the findings in Tables I and II indicate that sulphonamides and streptomycin are ineffective in N.S.U. of uncertain aetiology and that terramycin is of value in only 14 per cent. of cases. As most authors have found terramycin as effective a treatment as any (Table III), my findings also probably indicate that no treatment is of value in more than a small number of cases. Even those who disagree with my findings will find it difficult in the light of Table III to uphold the view that N.S.U. no longer presents any therapeutic problems. I suggest that knowledge of the subject will not be advanced until it is possible to recognize the types of urethritis which (1) clear quickly and spontaneously, (2) respond to treatment, or (3) run a prolonged course despite treatment.

\section{Summary and Conclusions}

Of 242 cases of non-specific urethritis of uncertain aetiology treated with potassium citrate, 78.7 per cent. recovered within 5 weeks. These cures were thought to be spontaneous rather than due to the potassium citrate. The cure rate in cases treated with potassium citrate was compared with that in cases treated with sulphonamides, streptomycin, and terramycin. It was concluded that sulphonamides and streptomycin were ineffective in non-specific urethritis of uncertain aetiology, and that terramycin was of value in only some 14 per cent. of cases. Because of the latter finding, it was also concluded that it was unlikely that any treatment would be of value in more than a small percentage of cases. 
REFERENCES

Babione, R. W., and Graham, R. S. (1952). Amer. J. Syph., 36, 480. Doyle, J. O., Gill, A. J., and Laird, S. M. (1957). Brit. J. vener. Dis., 33, 100.

Fowler, W. (1953). Ibid., 29, 166.

- and Knight, G. H. (1956). Ibid., 32, 2.

Gartman, E., and Leibovitz, A. (1955). Ibid., 31, 92.

Harkness, A. H. (1953). Ibid., 29, 134

Jelinek, G. (1957). Ibid., 33, 156.
Jensen, T. (1954). Amer. J. Syph., 38, 125.

Kershaw, P. S., and Lindsay, J. G. (1956). J. roy. Army med. cps, $102,56$.

Lyall, T. (1953). Brit. J. vener. Dis., 29, 151.

Prebble, E. E. (1957). Ibid., 33, 43.

Shaffer, L. W. (1954). Amer.J. Syph., 38, 349

Willcox, R. R. (1955). Brit. J. vener. Dis., 31, 89

Willcox, R. R. (1955). Brit.

(1956). Ibid., 32, 115.
(1957). Ibid., 33, 52 .

\section{BOOK REVIEW}

An International Nomenclature of Yaws Lesions. By C. J. Hackett. 1957. Pp. 104, 76 illustrations. World Health Organisation Monograph Series No. 36, Geneva. Available from H.M. Stationery Office, P.O. Box 569, London, S.E.1. (£1).

Descriptive dermatology in past generations was detailed, differentiating, and sometimes frankly imaginative. It tended to separate differing clinical manifestations which were subsequently found to have a common causation and to produce confusion of terminology even among nationals speaking their mother tongue; on the international plane confusion became worse confounded. Yaws, the treponematosis with a special predilection for skin and bone, is a case in point. The disadvantages arising from a confused nomenclature became specially significant in 1949 when the availability of long-acting penicillin preparations opened the way for national yaws-control campaigns in the major endemic areas of the world. In these mass campaigns agreed terminology is essential for teaching the para-medical personnel who will carry out the field work, for estimating the size of the problem in each area (which may well decide the treatment policy regarding latent cases and contacts), and for assessing the results found at re-survey. In particular, it is necessary to distinguish between those with early, infectious lesions, those with active late lesions, and those with inactive signs of past infection. The "Atlas of Framboesia" (WHO Monograph Series No. 5) produced in 1951 was the initial step to meet these needs, but the accumulation of additional knowledge has justified the production of a further monograph.

The present monograph has been compiled by Dr. Hackett in co-operation with an international group of experts on yaws and the participants at the International Conference on Yaws Control which was held at Enugu, Nigeria, in 1955. It defines the dermatological terms included in the nomenclature of yaws lesions suggested for international use and gives some synonyms hitherto employed. The international nomenclature and synonyms are clearly set out in two columns while a third column adds useful "remarks". The main part comprises 76 excellent black-and-white photographs of yaws lesions in Africans, which illustrate the lesions mentioned in the nomenclature. Although inexpensive, the book is well produced. It will be invaluable to those directly involved in yaws control throughout the world and will add much to the efficiency and success of such work. It will also interest the syphilologist dealing with immigrants from areas where yaws is or has lately been endemic. In fact, it should be studied by all those interested in the treponematoses and is a valuable contribution to the literature of this subject. 